\title{
JUANA CASTRO O LA VOLUNTAD DE UNA ESCRITURA FEMENINA
}

\author{
Ma Ángeles HERMOSILLA Ál VAREZ \\ Universidad de Córdoba
}

$\mathrm{H}$ asta bien avanzado el siglo XX, las mujeres escritoras se encontraron con un lenguaje literario que transmitía una tradición en la que ellas estaban escasamente representadas o bien presentaba modelos estereotipados de lo femenino, que a menudo se asociaban a lo trivial, cuando no a la sensiblería. De ahí que la palabra 'poetisa' alcanzara una carga peyorativa, de la que las literatas intentaron zafarse autodenominándose 'poetas'.

De este modo, las mujeres que tomaban la palabra observaban la paradoja de que eran «sujetos hablantes en un lenguaje que ya las ha construido como objetos» (Patrizia Violi, 1991: 14), de modo que la construcción de la subjetividad ha de realizarse a partir de la «deconstrucción» del orden patriarcal. Y es que la cuestión del «sujeto» es fundamental — sostiene Judith Butler (2001: 34) — para el feminismo porque, como señala Foucault, los sistemas jurídicos de poder 'producen' a los sujetos que después llegan a representar, de modo que la identidad es un 'efecto' de las prácticas discursivas (Id.: 51).

Por tanto, lo femenino es, en gran medida, una construcción cultural, según ha señalado el pensamiento postmoderno. En este sentido, la teoría feminista francesa afirma que la identidad sexual no es biológica, sino que responde a una posición cambiante del sujeto y autoras como Julia Kristeva (Toril Moi, 1986: 171 y ss.), dentro del feminismo de la diferencia, en vez de elaborar un teoría sobre lo femenino, ponen el acento en la marginalidad, la subversión o la disidencia, que parecen caracterizar a las escritoras cuando tratan de crear un sujeto poético propio.

Sin embargo, hasta fechas relativamente recientes, las autoras españolas, como norma general, no hallaron unas circunstancias propicias para plantearse el problema de la construcción de un yo poético femenino. Aunque pueda existir algún precedente aislado, se trata de una labor que emprenderán a finales de la década de los setenta del siglo pasado algunas poetas, entre las que destaca especialmente la cordobesa Juana Castro, que, como recoge Olvido García Valdés en el prólogo de la antología Heredad (Juana Castro, 2010 b: 11), se declara abiertamente seguidora del feminismo de la diferencia. Ya en su primer libro, Cóncava mujer (1978), situado en el panorama poético entre una poética realista y la que representaba el recuperado grupo Cántico, reflexiona sobre la condición de 
mujer, un tema clave que desde el principio ha señalado la crítica (Encarna Garzón, 1996:17 y 71 123), cuyo designio social, vinculado a lo reproductivo, pone en cuestión. Se inicia así una trayectoria literaria, jalonada de premios, que continúa con el libro Del dolor y las alas (1982), sobre el dolor por la pérdida del hijo; Paranoia en otoño (1985), premio Juan Alcaide del Ayuntamiento de Valdepeñas, poemario de exaltación de la pasión amorosa; Narcisia (1986), un canto a la divinidad femenina; Arte de cetrería (1989), premio Juan Ramón Jiménez, donde las imágenes de la caza reflejan las relaciones de poder; Fisterra (1992), del que un año antes se había publicado una primera edición con el título Regreso a Géminis (premio Bahía del Ayuntamiento de Algeciras) y en el que se rememora el paisaje rural de la infancia, tema presente también en Del color de los ríos (2000), accésit del premio Esquío de Poesía (Ferrol), en algunos de cuyos versos homenajea a sus antepasadas. Entre uno y otro, Juana había publicado No temerás (1994), premio Carmen Conde, una revisión de la figura bíblica de Salomé, que, a juicio de Vicente Luis Mora (Juana Castro, 2006: 11), supone «una construcción del sujeto femenino más madura y consolidada que en los libros anteriores».

De signo diferente son los poemarios El extranjero (2000), premio San Juan de la Cruz, que trata sobre el exilio, y Los cuerpos oscuros (2005), premio Jaén de Poesía, acerca de la enfermedad del Alzheimer, mientras que, por contraste, el erotismo lúdico caracteriza La bámbola. Intrusos en la red (2010), un libro que reúne poemas escritos veinte años antes.

Este recorrido por la obra poética de Juana Castro, que los lectores pueden seguir, por otro lado, en las antologías Alada mía (1996), La extranjera (2006), Vulva dorada y lotos (2009) o Heredad, seguido de Cartas de enero (2010), tal vez puede hacer pensar que, dada la variedad de temas tratados y de planteamientos estilísticos, se trata de una producción discontinua y dispersa. «Nada podría estar más lejos de la verdad — concluye Sharon Keefe Ugalde (2002: 12) —, porque su obra, en toda su diversidad, forma un cuerpo textual unitario» $y$, en esta línea, la autora norteamericana, coordinadora del libro que compila distintos trabajos sobre la escritura de nuestra poeta, coincide con sus colaboradores en el interés que ésta muestra por la subjetividad femenina (Id.: 12-13).

En efecto, desde el principio sus poemas critican la opresión de las mujeres y el papel que se les asigna en el orden patriarcal, como se observa en «María encadenada», perteneciente a Cóncava mujer:

Llora, pequeña.

Te están circuncidando en la belleza,

tus tenues agujeros de esclava

llora, pregonarán tu ser desde la sangre.

Te están atando al oro

para que no recuerdes

ni voluntad ni inteligencia,

para que seas eternamente la muñeca

presa de adornos y miradas. (Juana Castro, 2010 b: 35).

Y pronto adquieren un tono próximo a la disidencia o la subversión, rasgos de los que hablaba Kristeva más arriba y que cristalizan en algunos ejemplos muy ilustrativos del poemario Del color de los ríos. Así, en «La era» surge un sujeto poético denunciador de la coactiva ley del padre, que impide 
cualquier tipo de expresión y es entonces cuando, como afirma (Hélène Cixous, 1995: 54-55) «voz y escritura se trenzan $[. .$.$] hacen jadear el texto o lo componen mediante suspenso, silencios, lo afonizan$ o lo destrozan a gritos»:

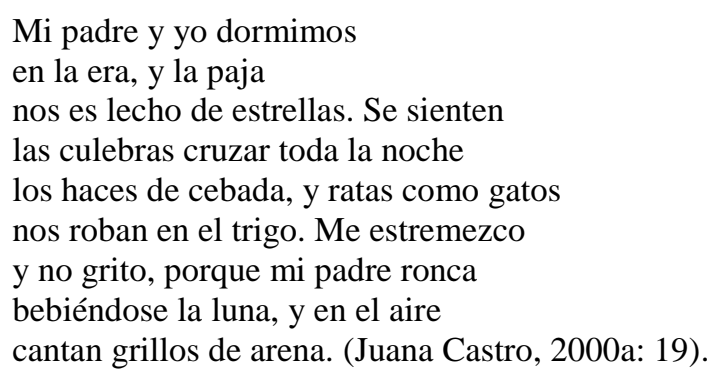

O en el poema «Padre», de título muy significativo, en el que el poder patriarcal es ejercido violentamente, idea que se expresa en una significante estructura circular:

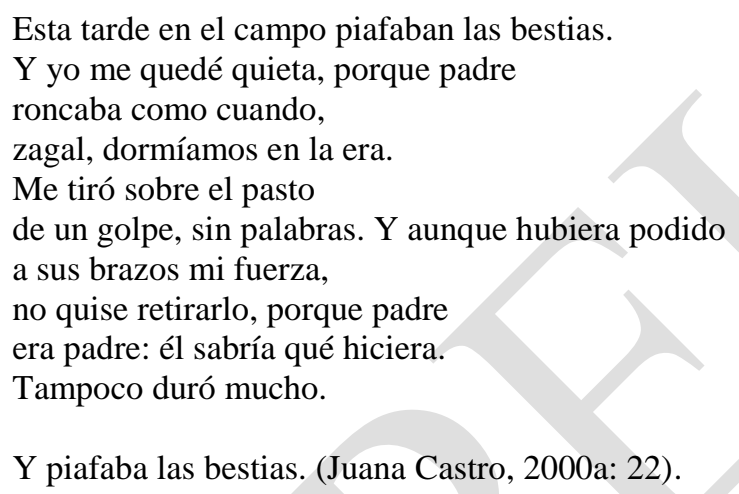

No obstante, nuestra escritora se percata enseguida de la dificultad de encontrar un lenguaje poético a través del que alcanzar una expresión propia, diferenciada de la utilizada por el varón, que, desconectada de la influencia materna, no logra construir su verdadera identidad —obsérvese el uso del sustantivo en masculino-, según se lee en «Zagal», poema asimismo integrado en Del color de los ríos:

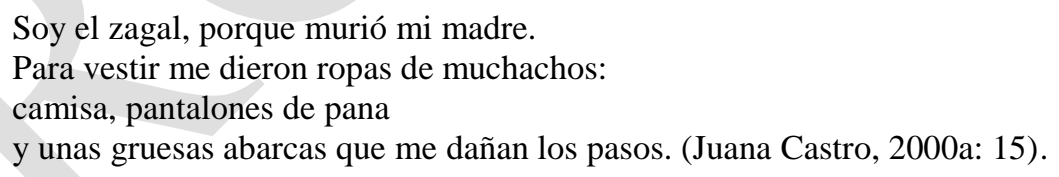

O en «Las trenzas», donde se prescinde del arreglo del cabello, que simboliza el cuidado materno, aunque el patriarcado lo haya convertido en un aspecto de seducción a los hombres ( $\mathrm{M}^{\mathrm{a}}$ Milagros Rivera, 1996: 63). En este caso, la eliminación de lo femenino da paso a la ley del padre, representada en el duro trabajo — adviértase la connotación del polisíndeton — desde la infancia, y no ausente, por la referencia a los sapos, de la referencia a la fealdad, la torpeza y la lujuria (Jean Chevalier, «sapo. $5 »)$ :

Mi tía me ha cortado las trenzas.

Ella dice

que un muchacho se debe peinar pronto. 


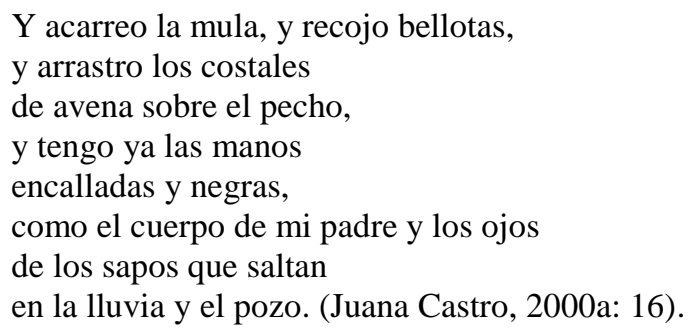

Por eso una de las tareas que Juana emprende es el reconocimiento de la madre, que, en este libro, se advierte en el diálogo que se establece con su progenitora en el poema «Madre», a la que, devolviéndole su dedicación, cuida con esmero en la vejez:

Y soy yo quien ahora te tiene, madre mía, a su merced turbada.

Diminutos tus huesos

y tu piel de ciruela que, si hablo, se rompe.[...]

Madre mía, mi niña, cúmplase esta oscura inversión, y tengamos tus cicatrices yo, tu corazón mis años. (Juana Castro, 2000a: 67).

O la reconstrucción de la genealogía femenina en el nombramiento de la cadena completa de las mujeres de la familia:

\section{SEPIA}

Ahora el tiempo me ha puesto color sepia la blusa y el dorado terrón donde cantaba

el libro de mis ojos. Estoy aquí, colgada en la pared de cal, con mi regazo breve dormido tras las tejas. [...] Soy tu abuela, la madre de tu madre, que vivió como tantas. Que dio a luz a tu cuerpo y te puso en las manos la existencia y el mundo. (Juana Castro, 2000a: 75).

Y, en No temerás, se concreta en la identificación con la figura materna:

CÁLIZ

Y ahora soy

tan igual a ti, madre, que no me conozco en el cristal de este retrato tuyo tan presente.

Si supieras que todo lo que de ti he odiado y maldecía ahora en mí lo descubro tan exacto y reciente como el cerco de una piedra en el agua, repetida. (Juana Castro, 2010b: 115).

Estas actitudes evitarían el matricidio (Luce Irigaray, 1985: 6 y 7) y restablecerían la autoridad de la madre (Luisa Muraro, 1991). 
Ya en Narcisia, mediante una riqueza de imágenes vegetales y de la naturaleza, heredera de los poetas de Cántico, trataba de crear un orden simbólico femenino, como postulaba Luce Irigaray (1978), en el que la nueva mujer, en cuyo cuerpo deliberadamente se repara, está dotada de atributos divinos:

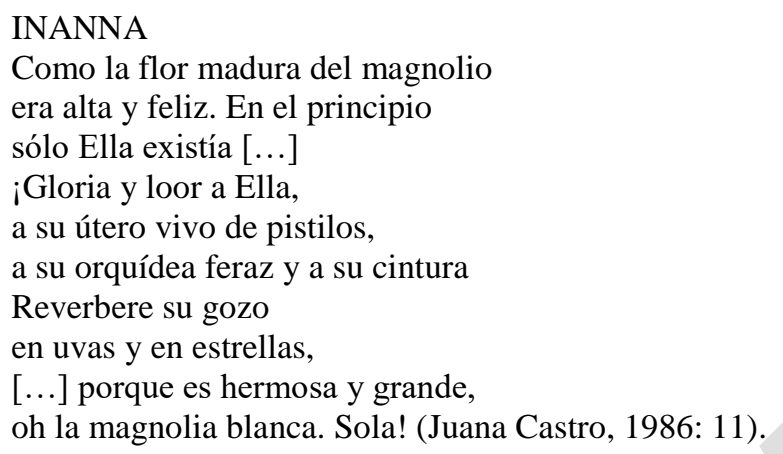

Se trata de una reinterpretación de los arquetipos y mitos que han sustentado la cultura occidental. En este sentido, destaca la revisión, en No temerás, del personaje bíblico de Salomé, contrapunto del patriarcado:

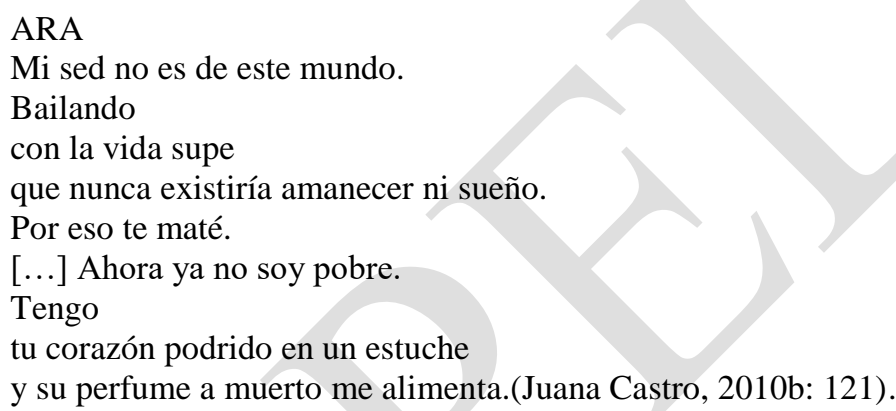

También de Dafne, en el poema del mismo título de Paranoia en otoño: «Que tu luz no me busque, Apolo, porque soy una hoja/ que vive con el viento» (Juana Castro, 2010 b: 53), en el que, en opinión de Olvido García Valdés, la diosa «pide ser árbol para no ser mujer, para no ser tomada, violada. [...] Mejor ser sin voz, que, siendo una persona, carecer de voz» (Juana Castro, 2010b: 23).

O de Penélope, en El extranjero, clara alusión a las mujeres afganas, en las que la espera del esposo se sustituye por la de la ansiada liberación:

\section{PENÉLOPE}

\section{Kabul}

Pajarillo enjaulado, me han quitado los ojos y tengo una cuadrícula calcada sobre el mundo. [...]

Noche mía del fardo que sin luces me arroja la esperanza del tiempo engastado en la letra. Noche mía, mi luz cuadriculada en negro, cómo pesa mi manto y su bordado, cuánto tarda la paz negra del cielo, cuánto tarda. (Juana Castro, 2000b: 71). 
Pero especialmente significativo es el caso de los cuentos infantiles, que suponen para la niña un aprendizaje de modelos idealizados como la boda de blanco, cuyo ritual se desenmascara en «María desposada», de Cóncava mujer:

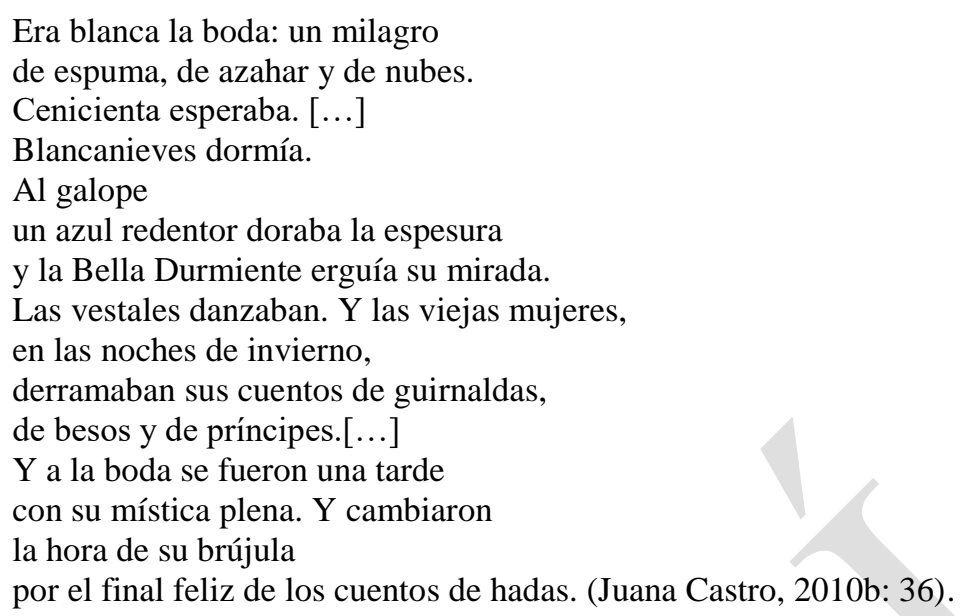

Otro mecanismo para resquebrajar el discurso falogocéntrico, en expresión derridiana, es el lenguaje místico, susceptible de albergar la disidencia, que se plasma en imágenes procedentes del Cantar de los Cantares en Narcisia, y se realiza plenamente en Arte de cetrería, de influjo sanjuanista:

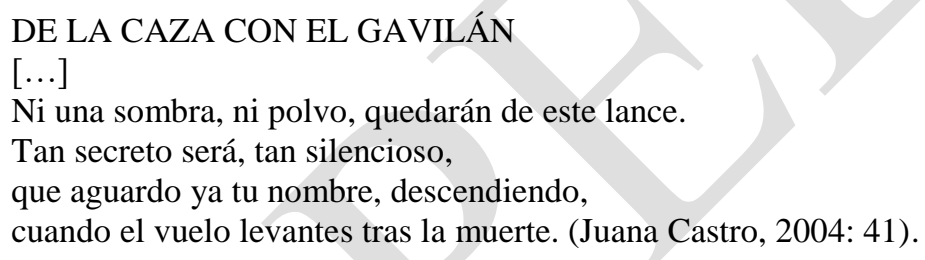

Es una fuente de inspiración, presente también en la modernidad desde los primeros románticos —Novalis, por ejemplo — hasta poetas de nuestros días, como Clara Janés en «Canto al amado», por citar solo una muestra, y supone, para el feminismo francés de la diferencia, la asunción de una 'escritura femenina', referida al estilo y no necesariamente a la firma de mujer (Hélène Cixous, 1995: 61). En la medida en que conlleva la disolución del sujeto en el objeto, es un estado hacia el que las mujeres se muestran proclives porque la posibilidad de ser sujeto es negada o reprimida por el discurso patriarcal. Nos hallamos, pues, ante una escritura indagatoria, errabunda, tendente a la disolución, pero germinal de un nuevo orden. Por ello no sorprende que Juana convirtiera el exilio en el tema central de El extranjero:

UNA HOJA

Sin tienda ni equipaje.

Te has plantado

delante de mi casa, cual si fuera

este suelo con nombre tu destino.

Por qué aquí.

Qué intención o qué viento

te arrastra u obedeces,

forastero. (Juana Castro, 2000b: 12). 
Ni que su voz, en la que se perciben ecos del baudeleriano albatros, ese «viajero alado [...] exiliado en la tierra», se identifique con la imagen del extranjero en el poemario No temerás, que conviene bien a la subjetividad 'nomade' que defiende la teórica de la tercera ola del feminismo de la diferencia Rosi Braidotti (2000: 31), entendida como un modo de despegarse del falocentrismo sedentario de la filosofía e iniciar la subversión de las convenciones intelectuales.

\author{
DESTIERRO \\ Yo no soy de esta tierra. \\ Era ya extranjera en la distancia \\ del vientre de mi madre \\ y todo, de los pies a la alcoba, me anunciaba \\ destierro.[...] \\ Sobre el mundo desvío, sé que voy, \\ como víbora en celo, persiguiendo \\ el rastro de mi exilio. (Juana Castro, 2010b: 113).
}

Un procedimiento distinto, pero que contribuye asimismo a la quiebra del sistema patriarcal es la ironía desestabilizadora, que transita por los versos de La bámbola, en los que el erotismo, a veces combinado con imágenes de las nuevas tecnologías, es el cauce elegido para parodiar los modelos que la publicidad ofrece en nuestra sociedad de consumo:

\author{
ES MI HOMBRE \\ Si usted, señora, es frígida \\ descanse ya, y recuerde: le ha llegado el momento. \\ Vendemos los orgasmos a granel \\ sin dependencia alguna. \\ Sin médico, sin drogas, sin gimnasia [...] \\ Nosotros le ponemos el placer. \\ Usted sólo el dinero. (Juana Castro, 2010a: 33-34).
}

O, en este otro ejemplo, que, contraviniendo la concepción canónica de la relación amorosa en la tradición literaria, avanza a través de una serie de imágenes novedosas hasta un final inesperado:

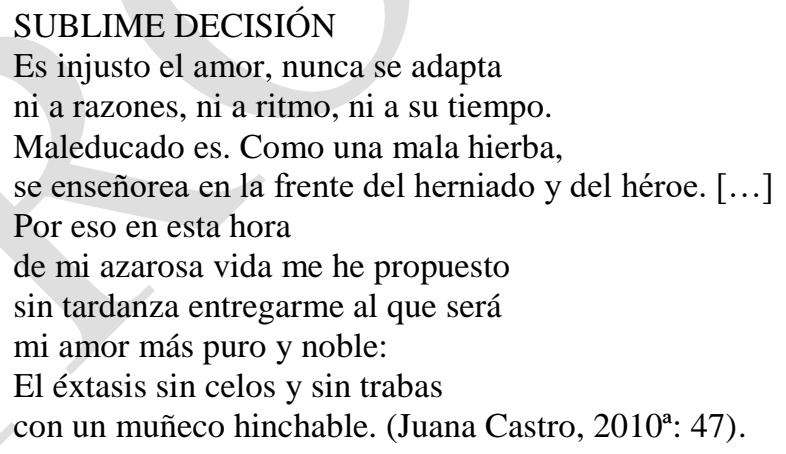

Esta sátira de actitudes y hábitos triviales de la vida social postmoderna aparece también en Valium 5 para una naranjada (1990), la obra en prosa de Juana Castro y, como en su poesía, trata de desmontar los estereotipos de un mundo que con frecuencia marginan o subyugan a las mujeres, pero que han encontrado en la obra de la escritora cordobesa una vía de denuncia o de subversión. Es la finalidad que preside también la lírica de otras autoras contemporáneas ( $\mathrm{M}^{\mathrm{a}}$ Ángeles Hermosilla, 
2011), que se valen de recursos similares a los que aquí hemos señalado. Pero justo es reconocer que ha sido Juana, creando, a partir de nuestra herencia literaria, un universo poético personalísimo, una de las primeras en haber abierto el camino.

\section{Bibliografía}

BRAIDOTTI, R. (1994): Sujetos nómades: corporización y diferencia sexual en la teoría feminista contemporánea. Buenos Aires/Barcelona/ México, 2000.

BUTLER, J. (1990): El género en disputa. El feminismo y la subversión de la identidad. Barcelona, México, Paidós, 2001.

CASTRO, J. (1986): Narcisia. Barcelona, Taifa. (1989): Arte de cetrería. Madrid, edic. La Palma, $2^{\text {a }}$ ed., 2004. (2000a): De color de los ríos. Ferrol, colección Esquío de poesía. (2000b): El extranjero. Madrid, Rialp, (2006): La extranjera, prólogo de Vicente Luis Mora. Málaga, Diputación (Puerta del Mar). - (2010a): La bámbola. Intrusos en la red. Jerez, EH editores.

(2010b): Heredad, seguido de Cartas de enero, prólogo de Olvido García Valdés. Sevilla, Fundación José Manuel Lara (Vandalia).

Cixous, H. (1995): La risa de la medusa. Ensayos sobre la escritura, prólogo de Ana María Moix. Barcelona, Anthropos.

Chevalier, J. (1969): Diccionario de los símbolos. Barcelona, Herder, 1986.

GARZÓN GARCíA, E. (1996): Temática y pensamiento en la poesía de Juana Castro. Córdoba, Servicio de Publicaciones de la Universidad.

Hermosilla Álvarez, Má Á. (2011): «La poesía de mujeres en España: la búsqueda de una identidad», Alfinge, 23, 2011, pp. 65-88.

IRIGARAY, L. (1974): Speculum de la otra mujer. Madrid, Saltés, 1978.

(1981): El cuerpo a cuerpo con la madre. Barcelona, La Sal, 1985.

MoI, T. (1986): Teoría literaria feminista. Madrid, Cátedra, 1995.

MURARO, L. (1991): L'ordini simbolico della madre. Roma, Editori Riuniti.

RIVERA, M. (1996): El cuerpo indispensable. Significados del cuerpo de mujer. Madrid, horas y HORAS.

UGALDE, S. K., ed. (2002): Sujeto femenino y palabra poética. Estudios críticos de la poesía de Juana Castro. Córdoba, Diputación.

VIOLI, P. (1991): El infinito singular. Madrid, Cátedra («Feminismos»). 